\title{
O Conceito de Direito Líquido e certo no Direito Administrativo
}

\section{ARNOLD WALD}

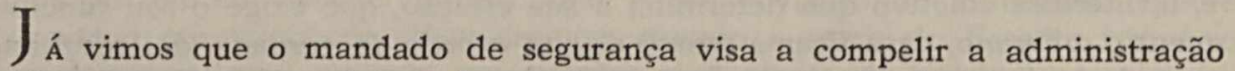
pública a praticar ou deixar de praticar certo ato. Não é pois um remédio reparatório, não é meio de ressarcir danos causados; o mandado de segurança modifica compulsòriamente uma situação dando ao impetrante direito à prestação in natura.
\end{abstract}

Já vimos que a Constituição de 1934 , no seu art. 113, n. $^{\circ} 33$, determinava que se desse mandado de segurança

"para a defesa de direito, certo e incontestável, ameaçado ou violado por ato manifestamente inconstitucional ou ilegal de qualquer autoridade".

O texto da Constituição vigente manteve o remédio processual "para proteger direito líquido e certo não-amparado por habeascorpus..., seja qual fôr a autoridade responsável pela ilegalidade ou abuso de poder".

Vemos que os pressupostos do mandado de segurança não variaram muito. Para que a medida possa ser concedida necessária se torna a existência de um direito líquido e certo, ameaçado ou violado, por ato ilegal ou abusivo de qualquer autoridade.

$\mathrm{O}$ direito protegido pelo mandado é aquêle que a lei e a jurisprudência definiram como líquido, certo e incontestáve1. Já se disse que o direito líquido e certo não era um conceito claro mas sim uma charada que os juízes resolviam ao sabor de suas própries convicções ou seja com ampla interpretação pessoal. Na realidade, o conceito foi elaborado inicialmente na jurisprudência referente ao habeas-corpus, que já tivemos o ensejo de estudar em capítulo anterior, cabendo a PEDRO LESSA a missão de definí-lo, pois, só concedia o habeas-corpus para proteção de direito certo e líquido que tivesse comc pressuposto a liberdade de locomoção.

Neste campo, o exame da jurisprudência e de sua evolução se torna necessário para poder compreender o sentido que atualmente os nossos tribun`is dão à expressão direito líquido e certo. 
Desde que surgiu o instituto os tribunais fixaram as premissas para o seu conhecimento. Assim, o mandado de segurança n.$^{\circ} 1$ do Supremo Tribunal Federal que data de 10 de setembro de 1934, afirmou que:

"Quer em face da doutrina, quer em face da Constituição que o consagrou, para que o mandado de segurança seja concedido é indispensável que seja certo e incontestável o direito ameaçado ou violado por ato manifestamente inconstitucional ou ilegal da autoridade". (1)

$\mathrm{Na}$ realidade não era necessária a dupla adjetivação já que todo ato inconstitucional é naturalmente ilegal. A terminologia empregada pela magna carta de 1934 se explica por motivos históricos já que houve quem quisesse dar ao mandado uma função mais restrita, limitando o seu âmbito de aplicação aos casos de evidente inconstitucionalidade do ato praticado pelas autoridades administrativas. Quando o constituinte decidiu ampliar a esfera de aplicação cio remédio processual conservou o adjetivo inconstitucional e depois acrescentou a expressão "ou ilegal".

$\mathrm{Na}$ Constituição de 1946, o problema já estava superado e o legislador não mais se referiu ao ato inconstitucional já abrangido no ilegal mas aludiu ao abuso de poder que é uma forma indireta de ilegalidade e ao qual já fizemos menção no estudo comparativo da doutrina francesa do detournement de pouvorr.

Apreciados assim os elementos indispensáveis para o conhecimento do mandado, vejamos a conceituação do direito líquido e certo ou certo e incontestável, na expressão da constituição anterior.

Em sentença de 11, de agôsto de 1934 que deve ser a primeira proferida em mandedo de segurança já que a própria Constituição foi promulgada em 16 de julho de 1934, o então juiz Francisco Tavares Da Cunha Mello, assim definiu o direito certo e incontestável:

"é aquêle contra o qual se não podem opor "mctivos ponderáveis" e sim meras alegações, cuja improcedência o magistrado pode reconhecer imediatamente, "sem necessidade de detido exame".

Tal terminologia foi mantida e desenvolvida em diversos acórdãos posteriores inclusive do Supremo Tribunal Federal (3) e dos Tribunais de Justiça Locais do Paraná (4) e de São Paulo. (5)

(1) Rio de Janeiro, 10-9-1934, Rel. Ministro Hermenegildo de Barros, Impetrante MAnoel Pinto De Rezende, in Archivo Judiciário, vol. 35, p. 245.

(2) Sentença do Juiz da $3 .^{a}$ Vara no Mandado de Segurança impetrado por AMÉrICO SÃo PAULO TôRRES, in Atchivo Judiciário, vol. 31, p. 505.

(3) V. do acórdão do Supremo Tribunal Federal no Mandado de Segurança n. 122 , impetrado por ALCIDES FIGUEIREDo DE MEDEIROS e em que foi relator o Ministro ataulpho DE PaIva, in Archivo Judiciário, vol. 38, p. 387.

(4) V. o Mandado de Segurança n. $0^{\circ} 17$ da Côrte de Apelação do Estado do Paraná, impetrado por Bernardo SABATE, contra o Prefeito Municipal de Curitiba, com acórdão datado de 10-1-1936, de que foi relator o Desembargador Hugo Simas, in Revista Forense, vol. 66, p. 566.

(5) Mandado de Segurança n. ${ }^{\circ} 52.939$, julgado pelo Tribunal de Justiça do Estado de São Paulo, sendo impetrante SHELl MEx, e relator o Desembargador J. C. DE AZEVEDO MARQUES, in Revista dos Tribunais, vol. 194, p. 297. 
Encontramos uma definição análoga em outros acórdãos do Supremo Tribunal Federal que afirmaram:

"O mandado de segurança só tem fundamento quando a violação de çireito individual é de tal ordem, clara e evidente, que exclui a n€cessidade de recorrer-se a interpretzções mais ou menos controvertidas para reconhecer-lhe procedência; esta deve defluir imediata e pronta do simples cotejo entre o fato e o mandamento destinado a regê-lo". (6)

No mesmo sentido é a definição dada pelo Tribunal de Justiça mineiro em acórdão da lavra do Ministro OROZIMBo NonATO, quando desembargador naquela côrte:

"Direito certo é incontestável é o que é sobranceiro a qualquer dúvida razoável e maior do que qualquer controvérsia sensata". (7)

Tem-se entendido pois que

"não se considera direito líquido e certo, capaz de ser protegido por mandado de segurança aquêle contra o qual se pode opor dúvida razoável ou fundada". (8)

E' preciso que o fato alegado pela parte e em que baseia o seu direito seja certo, tenha sido provado documentalmente, de modo absoluto e evidente. Assim, pouco importa a complexidade do problema jurídico discutido, indispensável é que o fato alegado esteja devidamente comprovado e dê ao impetrante o direito subjetivo cuja proteção requer ao juiz.

Assim,

"não se pode falar em direito certo e incontestável que justifique o mandado de segurança, quando a apreciação do direito do requerente depende de prova de fatos controvertidos". (9)

"O que não se admite no mandado de segurança é a alta indagação de fatos intricados, complexos ou duvidosos. O direito tem de ser certo. Mas o critério da certeza como o da clareza, é questão de apreciação individual. Excluir a controvérsia - qualquer controvérsia - seria destituir o mandado de segurança de qualquer alcance prático". (10)

(6) Mandado de Segurança n. $^{\circ} 88$, da Côrte Suprema de 5-1-1935, relator Ministro Otávio Kelly, in Archivo Judiciário, vol. 39, p. 263.

(7) Mandado de Segurança n. ${ }^{\circ} 13$ da Côrte de Apelação do Estado de Minas Gerais, in Revista Forense, vol. 66, p. 292.

(8) Recurso de Mandado de Segurança n. ${ }^{\circ} 1.156$, de 12-6-1939, da 2. ${ }^{\mathrm{a}}$ Câmara do Tribunal de Justiça do Estado de São Paulo, in Revista dos Tribunais, vol. 120, p. 79.

(9) Mandado de Segurança n. ${ }^{\circ}$ 616, julgado pela $2 .^{\text {a }}$ Turma do Supremo Tribunal Federal, em 5-9-1939, relator Ministro EduARdo EspínolA, in Archivo Judiciário, vol. 53, p. 319 .

(10) Recurso extraordinário julgado pelo Supremo Tribunal Federal, em 6 de outubro de 1941, sendo relator o Ministro OROzImbo NonATo, in Revista Forense, vol 92, p. 93 . 
A jurisprudência, quando sai de uma definição puramente lógica do conceito de direito líquido e certo, procura acentuar a necessidade de prova cabal dos fatos alegados sôbre os quais repousam as pretensões jurídicas. $\mathrm{O}$ direito certo e líquido é a pretensão jurídica com base legal estribada em fato amplamente demonstrado e comprovado.

"O mendado de segurança não comporta vacilação ou controvérsia acêrca de questões de fato e de prova. Só em havendo fato certo, estreme de dúvida, será possível apurar-se o direito que dêle promana, e neste caso terá cabida o mandado de segurança. A questão jurídica por intricada e controvertida que seja não retira a possibilidade de exame do remédio heróico".

A prova, afirmava a jurisprudência, deve ser cabal, completa e imediata.

Assim se entendeu que:

"Certo e incontestável é sòmente o direito que, ao ser invocado, se reveste de tôdas as características da evidência, não precisando ser demonstrado através de formalidades processuais, como a verificação pericial". (12)

"O mandado de segurança não é meio idôneo para o deslinde de direitos só elucidáveis por provas dependentes de dilaçổes demoradas". (13)

No mndado de segurança, não se admite

"a necessidade de provas complementares nem de maior exame elucidativo dos fatos". (14)

devendo os fatos serem apresentados sem deixar margem à dúvida, sem necessidade de exame pericial ou de outras proves futuras e eventuais. A certeza que se exige se refere ao direito subjetivo e não à norma agendi. (15)

E' preciso assinalar que recente jurisprudência já tem admitido perícia em mandado de segurança, abrindo assim um novo caminho na evolução do instituto e transfcrmando o próprio conceito de direito certo e líquido.

(11) Recurso em Mandado de Segurança n. ${ }^{\circ} 1.643$, do Tribunal de Apelação do Estado do Rio de Janeiro, 8-7-1946, relator o Desembargador IVAIR NogueIRA ITAGIBA, in Revista Forense, vol. 107, p. 319.

(12) Mandado de Segurança n. ${ }^{\circ}$ 45, julgado pela 2.a Câmara Cível do Tribunal de Justiça do Rio Grande do Sul, em 3-12-1947, sendo relator o Desembargador MELo FilHo, in Revista Forense, vol. 116, p. 200.

(13) Mandado de Segurança n..$^{\circ}$ 61, julgado pelo Tribunal Federal de Recursos, em 29-12-47, sendo relator o Ministro ARTUR MARINHo, in Arquivos do Tribunal Federal de Recursos.

(14) Mandado de Segurança n. ${ }^{\circ} 39.530$, julgado pela 3. ${ }^{a}$ Câmara Cível do Tribunal đe Justiça de São Paulo, em 16-9-1948, sendo relator o Desembargador CÂMARA LeAL, in Revista dos Tribunais, vol. 177, p. 151.

(15) Recurso de Mandado de Segurança n. 1.425 , julgado pelo Supremo Tribunal Federal em sessão plenária, de 1-8-1951, relator o Ministro Mário GuIMARÃes, in Revista Forense, vol. 148, p. 179. 
Na jurisprudência já consolidada, só se admite o mandado quando o fato alegado fôr certo e evidente, pouco importando a existência de divergência em relação à interpretação da norma jurídica. Assim, pocle justamente afirmar CAstro Nunes que a questão que, de um modo absoluto, pode excluir o mandado de segurança é a questão de fato.

Os acórdãos exigem a certeza e a prova imediata e completa do fato e do direito. $\mathrm{E}$ os princípios jurídicos alegados devem ser incontestáveis, não deixando a sombra de uma dúvida. A prova do fato não deve depender, numa interpretação rigorosa do texto legal, nem de provas testemunhais, nem de exames periciais, devendo ser feita completa e absolutamente nos documentos juntos pela impetrante à petição inicial. Devendo haver perícia, compreende-se que a prova do direito subjetivo e dos seus pressupostos não foi completa, não se tratando pois de direito líquido e certo, mas de direito a ser provado, não podendo pois ser protegido pelo mandado de segurança.

No mesmo sentido, manifestou-se a Côrte de Justiça do Estado do Rio:

"Líquido e certo é o direito que, ao ser invocado, se apresenta com tôdas as características da evidência concreta, não necessitando ser provado através de formalidades normais processuais". (16)

Vemos assim que numa primeira fase da evolução do mandado, caracterizou-se o direito certo e incontestável pela translucidez e pela evidência da pretensão jurídica. Posteriormente, admitiu-se o mandado como meio de resolver questões mais complexas desde que o fato alegado como base do direito subjetivo fôsse certo e provado inequivocamente pelos documentos juntos à inicial. Tal é o sentido da evidência concreta a que se refere a ementa do acórdão que acabamos de citar.

Naturalmente, essa evidência concreta é conceito subjetivo e relativo, variando de juiz para juiz. Aqui, como no direito suíço, o magistrado faz as vêzes de legislador, apreciando em cada caso concreto, a clareza meridiana que deve caracterizar o direito violado. A lei e a jurisprudência se limitam a dar uma diretriz e uma orientação, deixando ao arbítrio do juiz a solução de cada hipótese. O magistrado, no exame dos processos que the são submetidos, procurará fixar o seu próprio conceito de direito líquido e certo, assinalando o que para êle se torna evidente, natural, decorrente dos inabaláveis princípios jurídicos inerentes à nossa civilização. Tal é a razão pela qual nem sempre se justifica a revolta contra a concessão ou a denegação do mandado. O que é transparente, evidente e cristalino para o advogado, pode não sê-lo para o juiz. São problemas de formação pessoal, de ideologia, de escalas de valores. Indiscutìvelmente, há pretensões jurídicas, direitos subjetivos que gozam de garantias constitucionais que o legisledor não pode restringir. E' o caso, por exemplo, das garantias concedidas à magistratura, como a vitaliciedade a inamovibilidade e a irredutibilidade de vencimentos. Mesmo neste

(16) Acórdão de 6-7-1941, da Côrte de Justiça do Estado do Rio de Janeiro, citado por Oliveira e Silva, Aspectos legais do mandado de segurança, Rio de Janeiro, Imprensa Nacional, 1951, p. 9. 
campo, dúvidas algumas vêzes são suscitadas como no mandado impetrado por alguns juízes a fim de obter a isenção do pagamento do impôsto de renda, que foi denegado por se tratar de impôsto geral que recai sôbre todos os cidadãos.

Há outros domínios em que os conflitos entre a norma constitucional e a lei ordinária não permitem uma solução tão simplista. 'Torna-se difícil dizer se a lei apenas regulamentou o princípio constitucional ou se, ao contrário, reduziu garantias oferecidas pela Carta Magna. Tais dúvidas surgiram em relação ao dispostivo que encontramos no art. 142 , da constituição vigente e que permite a entrada e saída de nacionais e estrangeiros, em tempo de paz, com os seus bens e pertences.

Seria facultado à lei ordinária diminuir tal garantia constitucional? Tal é um dos problemas que tornou o mandado de segurança o instituto mais discutido da nossa época.

Mesmo em relação a princípios mais rígidos estabelecidos pela constituição vigente, como aquêle que veda a bitributação, dúvidas têm sido suscitadas dando margem a divergências jurisprudenciais em matéria de impôsto de cessão de promessas de venda, por exemplo. Enquanto a maioria dos juízes reconhece a inconstitucionalidade do malsinado impôsto, devemos destacar os votos vencidos de eminentes magistrados no próprio Tribunal de Justiça do Distrito Federal que em voto vencido defendem a legalidadè do tributo.

Uma oscilação maior existe em relação à cobrança do impôsto sôbre lucro imobiliário nos casos de venda de bens adquiridos mortis causa em que não houve preço de compra, com o qual não se pode equiparar o montante em que foi avaliado o bem na herança. Enquanto numerosos juízes, abraçando, a nosso ver, a melhor doutrina, concedem, neste domínio, medidas liminares, outros, não só indeferem os mandados de segurança, como também julgam improcedentes as ações ordinárias baseadas neste fundamento.

As substituições sucessivas dos juízes que transitam pelas Varas da Fazenda vêm dificultando sobremaneira a unidade e homogeneidade da jurisprudência referente aos mandados de segurança. A título meramente exempliticé tivo, assinalamos que na mesma semana o Dr. IvÂNIo DA CosTA CARVALHO CAIUMBI julgou improcedente uma ação ordinária que movíamos contra a Fazenda Nacional a fim de obter a restituição de impôsto de lucro imobiliário pago em bens adquiridos por herança, na 3. ${ }^{a}$ Vara da Fazenda Pública, e, na mesma vara, o Dr. Clóvis Rodrigues, concedeu-nos a medida liminar em mandado de segurança fundado nas mesmas razões, tendo sido a mesma a documentação apresentada nos dois casos.

Assim, vemos que a apreciação do juiz não pode deixar de ser subjetiva, como o assinalam vários acórdãos.

"Em tese, esclarece o Ministro OROzimbo NonATo, só não ministram matéria prima ao mandado de segurança as questões de fato de apuração intricada. Só estas são excluídas de plano, do círculo do mandado de segurança. O mais será conseqüêrncia da reação individual do juiz, em face da dıficuldade da tese, uma vez que, como já o disse Costa MANSo - se não. 
me engano - o direito é sempre certo e a interpretação sempre vária e duvidosa". (17)

Outro acórdão mais recente confirma essa maneira de ver da nossa jurisprudência, consubstanciada na voz autorizada do Excelso Pretório.

"A questão de direito pode, em princípio, encontrar solução no mandado de segurança, não importando as controvérsias suscitadas, se ao juiz parecer certo o direito do impetrante".

Não se justifica neste campo o brocardo interpretatio cessat in claris, por ser a interpretação não só a fixação do sentido da norma legal, com aspecto meramente declaratório, mas o enquadramento de certas situações reais dentro ou fora da esfera de aplicação de tal ou qual norma.

O Ministro Costa Manso procurou demonstrar com habilidade e poder de argumentação que o direito era sempre certo. Incerto só poderia ser o fato.

"O fato é que o peticionário deve tornar certo e incontestável, para obter o mandado de segurança. O direito será declarado e aplicado pelo juiz, que lançara mão dos processos de interpretação estabelecidos pela ciência para esclarecer os textos obscuros ou harmonizar os contraditórios. Seria absurdo admitir se declare o juiz incapaz de resolver de plano um litígio, sob o pretexto de haver preceitos legais esparsos, complexos ou de inteligência difícil ou duvidosa. Desde, pois, que o fato seja certo e incontestável, resolverá o juiz a questão de direito, por mais difícil e intricada que se apresente, para conceder ou denegar o mandado de segurança. (19)

A tese do Ministro Costa Manso é das mais simpáticas, porque, na realidade, importaria em denegação de justiça a recusa do juiz em conhecer o pedido de mandedo de segurança por complexidade excessiva da questão de direito. Jura novit curia.

Pode acontecer, todavia que, embora certo o fato, não haja imperatividade da lei, ou seja, determinação legal obrigando a autoridade a praticar ou cieixar de praticar certo ato em têrmos explícitos. Nesta hipótese, critica com sagacidade o Ministro CASTRo NUNES, o juiz não pode substituir-se ao legislador pera obrigar a autoridade a praticar ou deixar de praticar determinado ato a que não é ela obrigada em virtude de lei.

"Se a lei é obscura ou presta-se razoàvelmente a mais de um entendimento, não vejo como se possa compelir a autoridade a praticar ou abster-se de praticar ato da sua função". (20)

(17) Voto proferido no Supremo Tribunal Federal pelo Ministro ORozrmBo NONATO, em 22-11-1946, ap. OLIVEIRA E SILVA, ob cit., p. $10 . \quad$ z z zz

((18) Acórdão do Supremo Tribunal Federal no recurso extraordinário n. ${ }^{\circ} 10.249$, em 21-5-1948, sendo relator o Ministro Orozimbo Nonato, in Revista Forense, vol. 129, p. 424 .

(19) Voto do Ministro Costa Manso, no Mandado de Segurança n. ${ }^{\circ} 333$, de 9 de dezembro de 1936 .

(20) Castro Nunes, cbl citL, $5 .^{a}$ ed., p. 93. 
Cita o eminente magistrado a doutrina americana que só concede o writ quando há plain duty do funcionário para realizar o ato e determina que o ato não seja praticado quando o funcionário está agindo plainly beyond his power. (21)

Themístocles BRANDÃo Cavalcanti discorda por sua vez de Costa MANSO por entender que nem tôdas as questões jurídicas se revestem da mesma complexidade ou da mesma simplicidade, havendo algumas

"que podem ser resolvidas de plano, enquanto outras, de alta indagação, exigem maior debate, estudos mais aprofundados, sem falar na prova mais completa, quanto à sua qualidade e quantidade. O conjunto dêsses elementos de fato e de direito é que integra o instituto. A natureza da contestação, a profundida e a relevância de seus argumentos são outros tantos elementos que influem na caracterização do instituto. E a palavra incontestável foi incluída na lei para exprimir precisamente a medida da contestação e a influência que possa ter no espírito do julgador".

Não podemos concordar com o eminente publicista pátrio nas reservas que faz à lição de Costa Manso. Pensamos até que tais restrições não são oriundas do jurista mas do procurador da Fazenda que algumas vêzes desponta nas páginas de Themístocles Cavalcanti.

Preferimos ficar com Costa Manso já que não deve haver lacunas num sistema jurídico, constituindo êste uma unidade sistemática. Não é necessário, a nosso ver, que a determinação legal seja explícita como o quer CASTRo Nunes. Pode também ser implícita. E, por outro lado, lícito é recorrer às fontes subsidiárias da lei, como o determina a própria introdução ao Código Civil. O que o juiz não pode é, recebendo o fato que lhe apresentam as partes, negar-se a dar o direito, na fórmula pretoriana. Seria uma verdadeira denegação de justiça. A complexidade da legislação vigente ou a dificuldade jurídica sentida pelo juiz não podem prejudicar as partes. $\mathbf{E}$ o fato de remeter o lesado para as vias ordinárias por ser espinhosa a questão de direito parece ser critério subjetivo do juiz que acabaria deturpando completamente 0 instituto.

O fato deve ser certo. Deve ser provada a violação do direito subjetivo pertinente ao lesado. Esta prova deve ser completa e cabal.

E' o que afirma em outras palavras PONTES DE MIRANDa quando diz:

"Desde que, com os documentos juntos, fica patente o direito do suplicante, líquido e certo é o seu direito. Não deixa de ser certo e incontestável se a controvérsia estabelecida sòmente concerne à interpretação da lei ou a revelação do direito objetivo, porque aí a incerteza ou contestabilidade é só subjetiva, - é simples insuficiência do juiz. Por mais grave que seja a dúvida sôbre a questão jurídica, não torna não-certo e não-contestável o

(21) CASTRO NUNES, ob. e loc. cit. na nota anterior.

(22) Themistocles BRANDÃo Cavalcanti, Tratado de direito administrativo, 2. ${ }^{a}$ ed., vol. VI, Rio de Janeiro, Freitas Bastos, 1951, p. 292. 
direito das partes. A lei, a regra jurídica, incidiu quando devia incidir; trata-se agora de dizer o que é que incidiu, qual foi a regra. Se o juiz não está a par do direito, isso nada tem a ver com es relações jurídicas. Para que possa deixar de conhecer do pedido ou julgá-lo improcedente, denegando-o com funáamento em não ser certo e incontestável, é de mister que mostre ser incerto e contestável, objetivamente; nunca seria suficiente dizer que há dúvida sôbre o entendimento da lei ou sôbre qual a lei que tenha regido a relação jurídica, e ainda que haja discordância na jurisprudência.

A certeza e liquidez de um direito não podem resultar da dúvida quanto à lei que rege êsse direito, porque tal dúvida é subjetiva, existe e depende de condições interiores, de estados de consciência e de convicção dos juízes, e não da relação jurídica. Por mais duvidoso que se sinta o espírito do julgador na determinação da lei competente, isso não atua na situação jurídica que não passa, por êsse acidente psíquico do julg£dor, a ser incerta e contestável. O direito existe, ou não existe; mas, existindo, pode depender de provas em dilações, e então é incerto e ilíquido". (23)

$\mathrm{Na}$ realidade o direito objetivo pode amparar ou não determinada pretensão. jurídica, não havendo lugar para a dúvida. A dúvida tão sòmente pode existir em relação ao fato alegado pelo impetranite como bese do seu direito. A dúvida só pode existir em relação à situação em que o impetrante declara que se encontra quando, inicialmente, não foi provada de modo completo e inequívoco. Quer dizer que a dúvida só ze pode referir ao fato e nunca ao direito objetivo, à norma agendi.

Recente acórdão esclareceu sobremaneira os requisitos ou pressupostos ảo mandado, afirmando que:

"A liquidez e certeza do direito não decorrem de situações de fato ajustadas com habilidade, mas de sua apresentação, estreme de dúvidas, permitindo ao julgador não só apurá-lo, como verificar a violência praticada". (24)

Resumiu os requisitos necessários à existência do direito certo e líquido SEABRA FAgundes, mostrando que:

"Primeiro: as circunstâncias de fato a respeito das quais se pretende a incidência de certa norma legal, sejam demonstráveis com clareza transparente, através de prova que permita ao juiz firmar, desde logo, a certeza da sua existência. Segundo: o ato administrativo denegatório da prestação pretendida pelo administrado seja evidentemente contrário à Constituição ou à lei"'. (25)

(23) Pontes de Miranda, Comentários à Constituição de 1946, 2. ${ }^{a}$ ed., São Paulo, Max Limonad, vol. IV, p. 370.

(24) Mandado de Segurança $\mathrm{n}^{\circ}$ 2.942, julgado pelo Tribunal Federal de Recursos, em 20 de julho de 1953, relator o Ministro SAMpaio Costa, in Revista Forense, vol. 152, p. 169.

(25) SeAbra FAgundes, ob, cit., p. 228. 
São êstes os casos em que não pode ser negada a existência de direito liquido e certo. Outros há em que a matéria pode ser discutida por se tratar na realidade não de lesão de direito líquido e certo mas sim de desvio de poder, ou seja, de abuso de poder, quando são praticados atos formalmente legais, cujo móvel é, entretanto, contrário à mens legis .

Neste sentido, Oliveira E Silva se refere a uma decisão do Tribunal de Justiça do Rio Grande do Norte que concedeu um mandado de segurança a uma emprêsa de transporte coletivo para que não lhe fôsse impôsto horário inconveniente. O tribunal, no caso, saiu da exclusiva apreciação da legalidade pora considerar as razões, ou melhor, a falta de razão em que se fundamentou o executivo ao estabelecer o referido horário. Trata-se de uma extensão da proteção legal concedida não mais contra o ato ilegal mas também contra o abuso de poder, atendendo à própria letra do texto constitucional vigente . A ementa da referida decisão é a seguinte:

"Fere o princípio constitucional da igualdade de todos perante a lei, o ato da autoridade fiscalizadora do trânsito que impõe horários inconvenientes a uma emprêsa de transporte coletivo com a finalidade de favorecer emprêsa concorrente". (26)

E Silva :

Comentando a referida decisão, esclarece o Desembargador OLIVEIRA

"No caso levado ao julgemento da Côrte Rio Grandense do Norte, poder-se-ia alegar, em voto discrepante, que o ato da autoridade administrativa reputado prejudicial aos interêsses da emprêsa de transportes, poderia ser injusto, mas não ilegal". (27)

Procede inteiramente a ponderação do douto magistrado mas o caso é típico de abuso de poder. Não há dúvida que o ato em questão era contrário ao espírito da lei, que deturpou, dando-lhe objetivo diverso e oposto àquele que justifica a sua existência.

Defendemos essa ampliaçẽo do conceito de direito certo e líquido. Existe êle desde que evidentemente emana do sistema jurídico vigente, devendo ser concedido o mandado sempre que houver violação de direito certo e líquido, evitando-se assim que a lei seja violada ou que seja utilizada em sentido contrário à sua própria finalidade.

(26) Decisão do Tribunal de Justiça do Rio Grande do No te de 28-7-1948.

(27)

Oliveira e Silva, ob. cit., p. 11. 